\title{
Saudi Arabia's Healthy Food Strategy: Progress \& Hurdles in the 2030 Road
}

\author{
Faisal Fahad Bin Sunaid ${ }^{1}$, Ayoub Al-Jawaldeh ${ }^{2}\left(\mathbb{D}\right.$, Meshal Wasel Almutairi ${ }^{1}$, Rawan Abdulaziz Alobaid ${ }^{1}$, \\ Tagreed Mohammad Alfuraih ${ }^{1}$, Faisal Naser Bensaidan ${ }^{1}{ }^{(0)}$, Atheer Shayea Alragea ${ }^{1}$, Lulu Ali Almutairi ${ }^{1}{ }^{10}$, \\ Ali F. Duhaim ${ }^{1}$, Talal Ali Alsaloom ${ }^{1}$ and Jana Jabbour ${ }^{2,3, * \mathbb{D}}$
}

1 Healthy Food Department, Saudi Food and Drug Authority, Riyadh 13513-7148, Saudi Arabia; ffsunaid@sfda.gov.sa (F.F.B.); mwmotairi@sfda.gov.sa (M.W.A.); raobaid@sfda.gov.sa (R.A.A.); tmfuraih@sfda.gov.sa (T.M.A.); fnbensaidan@sfda.gov.sa (F.N.B.); asraqea@sfda.gov.sa (A.S.A.); lamutairi@sfda.gov.sa (L.A.A.); afduhaim@sfda.gov.sa (A.F.D.); tasalloom@sfda.gov.sa (T.A.A.)

2 Regional Office for the Eastern Mediterranean (EMRO), World Health Organization (WHO), Cairo 11371, Egypt; aljawaldeha@who.int

3 Nutrition Department, School of Health Sciences, Modern University of Business and Sciences, Beirut 113-7501, Lebanon

* Correspondence: jjabbour@mubs.edu.lb; Tel.: +961-3082793

\section{check for}

updates

Citation: Bin Sunaid, F.F.;

Al-Jawaldeh, A.; Almutairi, M.W.;

Alobaid, R.A.; Alfuraih, T.M.;

Bensaidan, F.N.; Alraqea, A.S.;

Almutairi, L.A.; Duhaim, A.F.;

Alsaloom, T.A.; et al. Saudi Arabia's Healthy Food Strategy: Progress \& Hurdles in the 2030 Road. Nutrients 2021, 13, 2130. https://doi.org/ $10.3390 /$ nu13072130

Academic Editor: Linda Monaci

Received: 19 April 2021

Accepted: 7 June 2021

Published: 22 June 2021

Publisher's Note: MDPI stays neutral with regard to jurisdictional claims in published maps and institutional affiliations.

Copyright: (c) 2021 by the authors. Licensee MDPI, Basel, Switzerland. This article is an open access article distributed under the terms and conditions of the Creative Commons Attribution (CC BY) license (https:/ / creativecommons.org/licenses/by/ $4.0 /)$.

\begin{abstract}
The Kingdom of Saudi Arabia (KSA) is a leading country worldwide in the prevalence of non-communicable diseases (NCDs), which alone can explain $73 \%$ of mortality in the country. In response to the heavy burden of NCDs, the Saudi Food and Drug Authority (SFDA), in collaboration with other government entities, developed a healthy food strategy (HFS) aimed at enhancing healthy lifestyles and reducing the intake of salt, sugar, saturated fatty acids (SSF) and trans fatty acids (TFA). The objectives of the HFS, to facilitate consumers' identification of SSF and reduce the SSF and TFA content in food items, were addressed in collaboration with key stakeholders in the public and private sectors of the food industry. These reforms included voluntary and mandatory schemes to display nutrition information in food and beverage establishments, display allergens on food menus, encourage the adoption of front of pack nutrient labels (FoPNLs) on food products, ban the use of partially hydrogenated oils and establish limits for sodium composition in breads and selected food products. This manuscript contextualizes the HFS and presents the results of monitoring initiatives undertaken by the SFDA to assess compliance with these reforms.
\end{abstract}

Keywords: health policies; nutrition; nutrient labels; trans fatty acids; non-communicable diseases; obesity; KSA; Eastern Mediterranean region

\section{Introduction}

With the unparalleled rise in non-communicable diseases (NCDs) in the twenty-first century, efforts have been put towards generating dietary guidelines, promoting health counseling and enhancing consumers' personal accountability [1]. With time, health care and governmental agencies have identified the multifactorial social determinants of obesity, which also involve legal reforms, industrial manufacturing and preparation in food and beverage establishments [2]. Recognizing their association with an increased risk of cancer, cardiovascular diseases, and overall mortality, sodium, added sugars, saturated fatty acids (SSF) and trans fatty acids (TFA) have been the main nutrients targeted in such policies and interventions [3-6]. The focus has been on increasing consumers' awareness of their health hazards, facilitating their identification by consumers and reducing their content in food items [2]. The United Kingdom (UK) set an example with an interdisciplinary multicomponent initiative to be followed with a salt-reduction program [7]. This strategy included awareness campaigns for the public, as well as legal reforms with the industry and food establishments, which ensured gradual and sustainable reductions in sodium 
content. Despite the trends of increasing sodium consumption worldwide, this program succeeded in reducing sodium intake in the UK by $15 \%$ over 7 years [7].

The Kingdom of Saudi Arabia (KSA), part of the Eastern Mediterranean region (EMR), is one of the fastest growing economies in the world. The escalation in household income in the beginning of the 21st century was accompanied with a fast nutrition transition and an increased consumption of SSF, associated with a heavy burden of obesity, food allergies, and NCD [8-11]. Recent data by the World Health Organization (WHO) and the Global Burden of Disease (GBD) revealed that KSA is among the top countries in the region and the world in the prevalence of obesity and diabetes. NCDs explain $73 \%$ of mortality and kill more than 900,000 individuals yearly, and high body mass index (BMI), prevalent in more than $65 \%$ of the population, is the leading factor of years lived with disabilities (YLD) in KSA [12-17]. Among children and adolescents, rates of overweight and obesity have also increased, exceeding $31 \%$ in this subpopulation [18-23]. NCDs have been estimated to burden the country, on an annual basis, with 19 billion United States dollars (USD) in direct costs and 13 billion USD in indirect costs from lost productivity [24]. In response to the heavy burden of obesity and NCDs, the KSA's government developed nutritional guidelines and strategies, the last of which was the healthy food strategy (HFS) established by the Saudi Food and Drug Authority (SFDA), as part of Saudi Vision 2030 [25]. The HFS, planned in September 2017 and officially launched in September 2018, incorporated a series of nutritional reforms and educational campaigns. This article aims to provide readers with an overview of the HFS reforms and the results of the monitoring initiatives. It is structured as follows: Section 2 describes nutrition reforms implemented prior to the HFS in the KSA; Section 3 presents a summary of nutrition policies implemented as part of the HFS; Section 4 reviews monitoring initiatives lead by the SFDA, and Section 5 discusses the HFS by comparing this study's findings to the literature on the subject.

\section{Review of Nutrition Reforms Prior to the HFS Implementation}

In 2012, the Ministry of Health established the Healthy Food Palm Dietary Guidelines to provide culturally relevant guidance to health care providers and individuals on healthy diets [26]. These food-based dietary guidelines, meant to be employed by health care providers and to be incorporated in awareness campaigns and schools' curricula, provided culturally relevant guidance on the recommended daily food-group intake by age category [26].

In KSA, all edible products need to comply with the guidelines of the Gulf Standardization Organization (GSO) and the SFDA [27]. The GSO issues two forms of governing documents: technical regulations that substitute for national policies and standards, the adoption of which is optional for member nations [28]. In 2013, the SFDA enforced general labeling requirements on prepackaged food items, exported and locally produced, available in the country's market. Products needed to have a comprehensive list of ingredients written in descending order in Arabic [28]. In 2018, the SFDA, in line with the GSO's technical regulation, imposed an updated nutritional-labeling requirement on all prepackaged food and beverages available in the Saudi market [28]. This regulation enforced the display of all macronutrients, including total fat, saturated fat, total carbohydrates, total sugar and sodium, as well as selected vitamins. This regulation excluded items that had negligible amounts of macronutrients, SSF and TFA, such as spices, small packages, fresh fruits and vegetables, as well as packages that had single nutrients and/or ingredients. Fresh and chilled meats, poultry and fish were also excluded from this regulation as well as products sold to consumers from preparation points (e.g., in restaurants and coffee shops) [28]. Recognizing the health hazards of TFA consumption, the SFDA sat an upper limits for TFA of $2 \%$ in fats and oil products and 5\% for other products in 2015 [29]. A grace period was provided for manufacturers to adapt the composition of food products until 2017, when the TFA limits were enforced as a regulation. Finally, because KSA residents were identified as the fifth largest consumers of sugar-sweetened beverages (SSB) in the world, a flat sin tax was imposed by the General Authority of Zakat, Tax and Customs (GZAT) on 
carbonated and energy drinks in 2017 [30,31]. The latter reform lead to a reduction in sales of carbonated beverages by around 33\% compared to untaxed beverages in KSA [32]. All in all, cross-sectional studies revealed that despite the implementation of several reforms and the successful reduction in carbonated drinks consumption, the gap remained large between dietary recommendations and goals in KSA. Less than $10 \%$ of assessed individuals met the recommendations for fruit and vegetable intake; less than $50 \%$ complied with the guidelines for fish consumption in 2013, and salt intake was $9.3 \mathrm{~g}$ /day in 2016, almost double the relevant $\mathrm{WHO}$ recommendation of $5 \mathrm{~g} /$ day $[11,33]$.

\section{The HFS: Description of the Health Reforms}

In 2017, the SFDA moved from setting individual regulations to conceptualizing the HFS, a wider strategy that aimed at improving nutritional and health indicators. While the SFDA took the lead in establishing the whole strategy, it collaborated with key governmental entities (e.g., the ministry of health, ministry of municipality, ministry of environment, water and agriculture, as well as the key ruler) and universities and ensured the buy-in of private entities such as food manufacturers and establishments. Components of HFS reforms included the elimination of industrial TFA and the reduction of the SSF content in food items, the empowerment and education of consumers and the enhancement of public awareness in partnership with food establishments and the food industry. Our research team reviewed HFS-related policies and surveillance reports published by the SFDA. Table 1 and the following section summarize the voluntary and mandatory schemes that were established under the HFS umbrella. The majority of regulations provided a grace period for collaborators between issuance and enforcement. During this time, the SFDA generated guidelines that were relevant to the regulations, implemented educational interventions to raise awareness among consumers and provided workshops for collaborators to discuss and clarify the regulations.

\subsection{Display of Nutrition Information and Regulation of Juice Compositions in Food and Beverage Establishments}

To empower individuals to make healthy decisions when eating out, the SFDA invited all food establishments in KSA (restaurants, hotels and coffee shops) in 2017 to display caloric information on their menus and to have their meals' nutrient compositions available for each item in the establishment to answer customers' inquiries [34]. To make caloric information relevant to the consumers, menus also included the recommended caloric intake for adults and children. This voluntary approach, which progressed to a mandatory scheme in 2019, provided several options to food establishments to calculate the caloric content of the offered items: analysis in a certified food laboratory, use of a list of approved mobile applications and/or consultation with a licensed dietitian [34]. The display of caloric content was the legislation that required the largest number of workshops across the KSA, because the food establishments found it challenging to calculate the nutrient composition of their meals. During these workshops, the food industry representatives expressed concern over the cost of the analysis of meals in laboratories. The SFDA, in its turn, developed a free website facilitating the calculation of nutrient composition [35]. The display of food allergens on food establishment menus, enforced in the same year, aimed to empower consumers suffering from food allergies to make healthy choices and to prevent allergic reactions. This regulation, enforced in 2019, required food establishments to list 14 common food allergens on their menus [36]. The SFDA also targeted juice shops and outlets with a regulation in 2020 that mandated the display of nutrient labels on juice products. This regulation controlled the preparation and nutrient composition of added sugars in fresh juices, nectars and fruit drinks [37] (Table 1). 


\subsection{Front of Pack and Back of Pack Nutrition Labelling}

The difficulty of comprehending information on nutrition labels led many governmental agencies to adopt different types of labels allowing consumers to make quick and informed decisions while shopping [38]. In 2018, the SFDA invited local and international manufacturers to join a voluntary pledge to apply front of pack nutrition labels (FoPNL) on prepackaged foods [39,40]. The recommended FoPNL featured the multiple traffic light (MTL), which uses red, amber and green colors to reflect elevated, moderate and low composition of selected nutrients, respectively [41]. MTL was used for SSF and total fat content expressed per $100 \mathrm{~g}$ or per $100 \mathrm{~mL}$. On the same topic of nutrient labeling, and as previous policies did not mandate the display of TFA, added sugar, total cholesterol and fiber on food products' nutrition information [28], a policy enforcing their display on the back of pack label on all food manufacturers was issued as part of the HFS [42]. During the grace period, when discussing the reforms with the SFDA, food manufacturers were concerned about the lack of time to analyze and display the additional nutrients. The SFDA hence provided several extensions before enforcing this legislation.

\subsection{Trans Fatty Acid Regulations}

Following up on the TFA limits enforced in 2017, the SFDA decided to ban all partially hydrogenated oils (PHO) for use in food manufacturing. The SFDA signed a voluntary agreement with representatives of the food industry in 2018 [29]. The SFDA supported the food industry by increasing the supply of healthy fats and oils in the market and by conducting workshops to educate manufacturers on strategies to replace $\mathrm{PHO}$ with healthier alternatives. In 2020, with the enforcement of this regulation, the KSA became the first country in the EMR to have a "best practice TFA policy" that imposed the elimination of industrially produced TFA in food products [6].

\subsection{Restricting Sodium Content in Food Items}

In 2019, with the aim of reducing sodium content in food items, the SFDA enforced a limit of $1 \mathrm{~g} / 100 \mathrm{~g}$ for breads and for ayran (a traditional yogurt drink rich in salt) on manufacturers $[43,44]$. This regulation was followed in 2019 with an invite from the SFDA to food manufacturers to abide by limits for sodium content for 22 processed food items, inspired by limits set by Public Health England $[45,46]$. During educational workshops, small-scale bakeries expressed concerns on how to modify the content of breads without affecting their stability. SFDA supported these manufacturers by providing them with relevant recipes.

\subsection{Sin Tax on all SSB}

After the implementation of a flat tax on carbonated and power beverages, the GZAT, in collaboration with SFDA and under the umbrella of the HFS, extended the tax to include all SSB including flavored sweetened milk, juices, etc. [47]. The flat tax, enforced in 2019, involved a $50 \%$ tax on all SSB and carbonated beverages compared to a $100 \%$ tax on energy drinks. 
Table 1. Regulations and pledges of the Healthy Food Strategy.

\begin{tabular}{|c|c|c|c|}
\hline Policy Description and Reference & $\begin{array}{l}\text { Type of Policies and Relevant Dates of } \\
\text { Enactment and/or Enforcement }\end{array}$ & Key Collaborators & Policy Goal \\
\hline $\begin{array}{l}\text { Display of caloric information on food and beverage products in } \\
\text { menus of food establishments (restaurants, hotels and coffee shops). } \\
\text { SFDA.FD } 20 \text { [34] }\end{array}$ & $\begin{array}{l}\text { Voluntary pledge in } 2017 \\
\quad \text { Enforced in } 2019\end{array}$ & $\begin{array}{l}\text { Food establishments (restaurants, hotels and } \\
\text { coffee shop companies) }\end{array}$ & \multirow[t]{2}{*}{$\begin{array}{l}\text { Empower individuals to make healthy } \\
\text { decisions when eating out. }\end{array}$} \\
\hline $\begin{array}{l}\text { Declaration of allergens on food establishments' menus. } \\
\text { SFDA.FD 56 [36] }\end{array}$ & $\begin{array}{l}\text { Issued in } 2018 \\
\text { Enforced in } 2019\end{array}$ & $\begin{array}{l}\text { Food establishments (restaurants, hotels and } \\
\text { coffee shops) }\end{array}$ & \\
\hline $\begin{array}{l}\text { Regulation of nutrient composition in fresh juices, nectars and fruit } \\
\text { drinks and their display on products. } \\
\text { SFDA.FD 5001 [37] }\end{array}$ & $\begin{array}{l}\text { Issued in } 2019 \\
\text { Enforced in } 2020\end{array}$ & $\begin{array}{l}\text { Food establishments (restaurants, hotels, } \\
\text { coffee shops, juice shops and supermarkets } \\
\text { that sell juices) }\end{array}$ & $\begin{array}{c}\text { Encourage food and beverage establishments } \\
\text { to withhold adding sugars to juices. } \\
\text { Reduce consumption of sugars and empower } \\
\text { individuals to make healthy choices while } \\
\text { eating out. }\end{array}$ \\
\hline $\begin{array}{l}\text { Display of front of pack nutrition labels on prepackaged foods for } \\
\text { sugar, sodium, saturated fat and total fat. Encourage the use of } \\
\text { multiple traffic light labeling, a graphical illustration allowing } \\
\text { individuals to understand nutrient composition from a color code. } \\
\text { SFDA.FD } 42 \text { [40] }\end{array}$ & Voluntary scheme in 2018 & Food manufacturers & \multirow{2}{*}{$\begin{array}{l}\text { Encourage manufacturers to display nutrient } \\
\text { content in a comprehensible way to } \\
\text { consumers. } \\
\text { Empower individuals to make healthy } \\
\text { choices while shopping. } \\
\text { Reduce consumption of added sugars. }\end{array}$} \\
\hline $\begin{array}{l}\text { Mandate for back of pack nutritional labels that display the added } \\
\text { sugar, total cholesterol, fiber and TFA on prepackaged food items. } \\
\text { SFDA.FD } 2233 \text { [42] }\end{array}$ & $\begin{array}{l}\text { Issued in } 2018 \\
\text { Enforced in } 2021\end{array}$ & Food manufacturers & \\
\hline $\begin{array}{l}\text { Mandate for a sodium limit for breads and }(1 \mathrm{~g} / 100 \mathrm{~g}) \text { and ayran } \\
\text { (yogurt drink) }(1 \mathrm{~g} / 100 \mathrm{~g}) \\
\text { SFDA.FD 2362 [43] } \\
\text { SFDA.FD 57 [44] }\end{array}$ & $\begin{array}{l}\text { Issued in } 2018 \\
\text { Enforced in } 2019\end{array}$ & Food manufacturers & \multirow{2}{*}{$\begin{array}{l}\text { Collaborate with manufacturers to } \\
\text { reformulate their products to reduce sodium } \\
\text { composition. } \\
\text { Reduce sodium consumption. }\end{array}$} \\
\hline $\begin{array}{c}\text { Recommendation of a sodium limit for } 22 \text { processed food categories: } \\
\text { cheeses, butter, fat spreads, beans, cooked and canned soups, ready } \\
\text { meals, pizza, cakes, table sauces, biscuits, pasta, canned fish, meats, } \\
\text { canned vegetables, chips, cooking sauces, potatoes, flavor enhancers } \\
\text { and beverage powders. } \\
\text { SFDA.FD } 59 \text { [46] }\end{array}$ & Voluntary scheme in 2018 & Food manufacturers & \\
\hline $\begin{array}{l}\text { Enforcement of a flat tax of 50\% on all sugar-sweetened beverages, } \\
\text { including carbonated drinks, juices, and dairy products [47]. }\end{array}$ & Enforced in 2019 & General Authority of Zakat, Tax and Customs & $\begin{array}{l}\text { Reduce sugar-sweetened beverages } \\
\text { consumption. }\end{array}$ \\
\hline
\end{tabular}




\subsection{Educational Campaigns}

Several educational campaigns were launched by the SFDA, as part of the HFS, to promote healthy diets among consumers. Some of these campaigns were implemented in the workplace. The first initiative targeted food establishments in governmental and non-governmental agencies to increase fiber intake and to reduce SSF and TFA intake in the served meals and beverages. This campaign, initiated in 2019, involved a ban on the sale of carbonated beverages and the use of palm and coconut oil in food preparation, encouraged healthy cooking methods, replaced juice drinks with fresh drinks and included labels on sugar and salt packets with the WHO-recommended daily limits for the establishments adopting it. It also encouraged the wider availability of fiber-rich food sources and low-salt alternatives and the inclusion of healthy alternatives for sweets in their menus. Corporate food establishments across the KSA interested in this initiative were invited to sign up with the SFDA and implement it in their corporate restaurants and coffee shops. Another initiative in the workplace was recently launched as a collaboration between the Food and Agriculture Organization (FAO) and the SFDA to celebrate the fruit and vegetable (F\&V) year [48]. This initiative, launched in April 2021, aimed at increasing the awareness of the health benefits of $F \& V$ in the workplace and the importance of limiting their waste. It involved sharing nutrition-education material and infographics via email and on screens in the firms. It also promoted the distribution of $F \& V$ to the offices and making them available in the areas where breaks are taken. This campaign encouraged corporate food establishments to include more F\&V options on their menus, incorporate the logo for the international year for $F \& V$ on products produced in the food establishments, such as coffee cups and juices. Funding for these campaigns had to be done by the firms themselves.

Another campaign focused on food establishments providing delivery services. It incorporated a limit for calories, sodium, added sugar and the total fat composition of meals, as well as a reduction in portion sizes. This campaign targeted consumers by designing and distributing a guide for healthy meals allowing them to assess how healthy a meal is by comparing its composition to the WHO recommendations. Establishments that had meals that abided by the set limits were granted the privilege by the SFDA to label the meal as a "Balanced Meal". In addition to these campaigns, the SFDA lead several initiatives to educate the public on healthy-eating habits via live events and through their social media networks.

\section{Assessment of the HFS Acceptance and Implementation}

To monitor the compliance rates with the HFS reforms, the SFDA conducted a series of surveillance campaigns. These surveillances were either conducted in the city of Riyadh, the capital of the KSA, to provide preliminary insight or at the national level across five regions in the kingdom. Non-compliance with the mandatory regulations was treated as a legal violation by the SFDA. As for the non-mandatory, voluntary pledges, poor compliance was addressed by the SFDA with encouragement to comply with recommendations.

\subsection{Assessment of Nutrient and Allergens Information in Food Establishments}

National inspection campaigns monitored the compliance of food establishments with the HFS regulations. The first campaign conducted in 2019, targeted food establishments (restaurants, coffee shops, ice cream shops, fresh juice shops, corporate cafeterias and bakeries), assessing if they calculated nutrients and displayed calories on their menus. Inclusion criteria included food outlets with five or more branches in KSA. Data collected on 1363 establishments revealed that $27 \%$ did not display caloric content; $25 \%$ had incomplete display of caloric content, and $19 \%$ had incorrect calculation. A similar national campaign conducted in the same year assessed the compliance of food establishments with the display of food-allergen information. Findings revealed that $37 \%$ were not compliant with declaring food allergens on their menus. Finally, surveillance assessing restaurants, juice and coffee shops' compliance with the juices regulation was conducted in 2020. Results 
showed that $60 \%$ of establishments did not display calories on the food menus and/or used sweeteners in the preparation of fresh juices.

\subsection{Front of Pack Nutrition Labels Evaluation}

A year after inviting manufacturers from the private sector to join the voluntary pledge to include FoPNL on their products, the SFDA assessed products for the availability and the type of FoPNL employed. In the period extending from March 2019 until March 2020, the SFDA surveilled food products through a secondary data analysis of a dataset that it managed with information and pictures on food and beverage products available in the Saudi market. Products that included FoPNL were included. Exclusion criteria included product duplicates and those that had different flavor and/or size. Data were collected on the name and brand of the product, food category, type of FoPNL employed, manufacturing company type (local or international) and nutrient composition (SSF content). Products from 4335 companies were screened and 80 companies (1.8\%) had FoPNL on 119 unique products. Beverages were most likely to have FoPNL ( $30 \%$ of analyzed products), followed by dairy products $(23 \%)$ and confectionaries $(13 \%)$ (Supplementary Table S1). Most companies employed Guidelines Daily Allowance (63\%), followed by MTL (36\%), and a Health Star Rating (1\%). It is worth noting that the majority of products that displayed MTL had a low content of salt, saturated fat and total fat. The sugar content of these products was mostly moderate ( $40 \%$ of products) and elevated ( $42 \%$ of these products). Most of the products using MTL (65\%) were compliant to the SFDA recommendation of displaying the FoPNL per $100 \mathrm{~g}$ or $\mathrm{mL}$.

\subsection{Surveillance of the Sodium Content in Breads and Food Products}

The SFDA conducted national surveillance in 2019 after the regulation on sodium limits in breads was enforced. It involved an assessment of the nutrition label of bread products in bread factories, automatic bakeries and semi-automatic bakeries. The results revealed that, out of the 297 products assessed, $85 \%$ were compliant with the advised sodium limit of $1 \%$.

To monitor the compliance of food producers with the salt-limit recommendations set by the SFDA, a surveillance of food products available in supermarkets was conducted in the city of Riyadh in October 2020. Compliance was evaluated by comparing the products sodium composition from the nutrition labels in three supermarkets. These supermarkets were selected as they were the most visited supermarkets in the capital. Products $(n=267)$ were assessed, and 261 were included from 21 food categories, with $47 \%$ found to be compliant with the relevant SFDA recommendations. Compliance ranged from $0 \%$ for ready-made meals to $100 \%$ for pasta products. Kaak (breadsticks with toasted sesame seeds), cereals, potatoes, cheeses, canned beans and vegetables, meats (fresh and processed), ready-made meals, seasonings and flavorings had more than $50 \%$ of their products exceed the sodium limit sat by the SFDA (Figure 1). There were variations in compliance rates within some groups. For example, within the meat group, all fresh ground meat items were compliant with the sodium limits, whereas $25-50 \%$ of pastries prepared with meats, hamburgers and all of the processed meats were non-compliant with the SFDA sodium recommendations. Within the labneh group, $80 \%$ and $25 \%$ of full-fat and low-fat labneh products, respectively, were compliant with the sodium limits.

\subsection{Surveillance of SSF in Children Food Products}

A surveillance campaign in supermarkets in KSA's capital, Riyadh, assessed the compliance of food and beverage products targeting children with SSF guidelines. Supermarkets $(n=3)$ were selected based on their popularity, using the same criteria as the sodium-surveillance campaigns. Products that included toys and/or that featured the picture of a cartoon character were included in the surveillance campaign. Exclusion criteria included products for which consumption is advised by health authorities and those known to be low in SSF (e.g., unflavored milk). Nutrient composition of the included 
products was compared to the WHO guidelines (limits: $10 \%$ for saturated fats and added sugar, $30 \%$ for total fat, $1 \mathrm{~g} / 100 \mathrm{~g}$ for salt). From the screened items $(n=294), 18$ products were excluded because they had incomplete nutrition information. All products had a cartoon character featured, and $6 \%$ had toys included with the products. Of the included products, $91 \%$ had at least one nutrient that exceeded the recommended limits. Figure 2 showcases the percentage of products exceeding WHO limits for SSF and total fat by food category. All assessed products in the sweets and cereals categories exceeded the sugar limit. Similarly, all products in the chicken nugget, potato chip, and popcorn groups exceeded the salt limit (Figure 2).

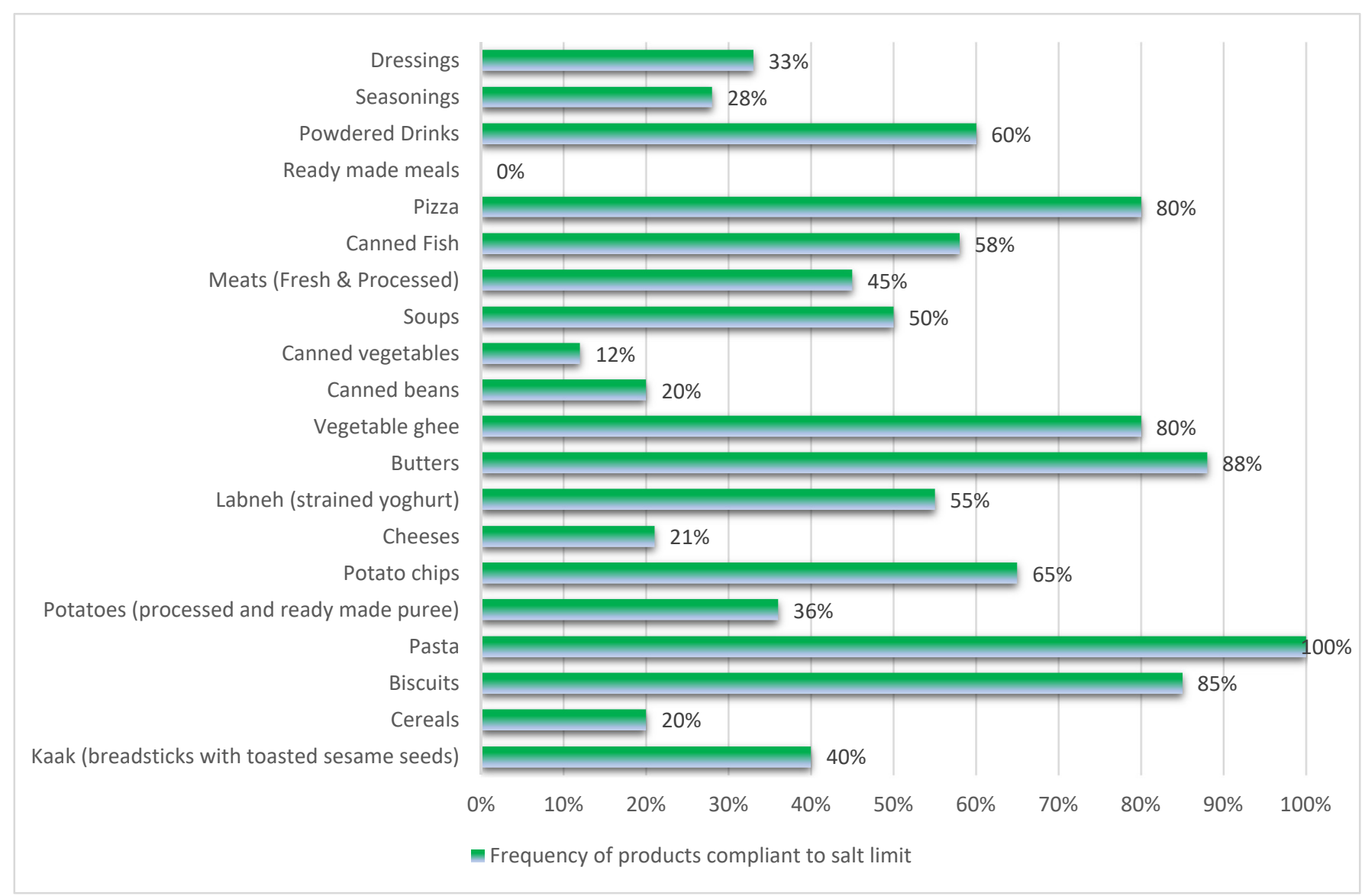

Figure 1. Frequency of products compliant with the salt limit.

\subsection{Surveillance of TFA in Food Items}

In July 2020, a national inspection campaign was conducted by the SFDA to assess the compliance of food manufacturers with the TFA regulations. Assessment was done by reviewing the manufacturing techniques and the ingredients to evaluate their $\mathrm{PHO}$ content. In case of inconsistency between manufacturing techniques and nutrient labels, laboratory analysis of food products was conducted through high-performance liquid chromatography (HPLC). Out of the 1117 manufacturers evaluated, 37\% were local manufacturers, and 7\% had non-compliant products. Of the assessed items, $20 \%$ were non-compliant because they had TFA containing ingredients that were not mentioned in the product information and/or because the nutrient labels did not reflect the correct nutritional analysis. 


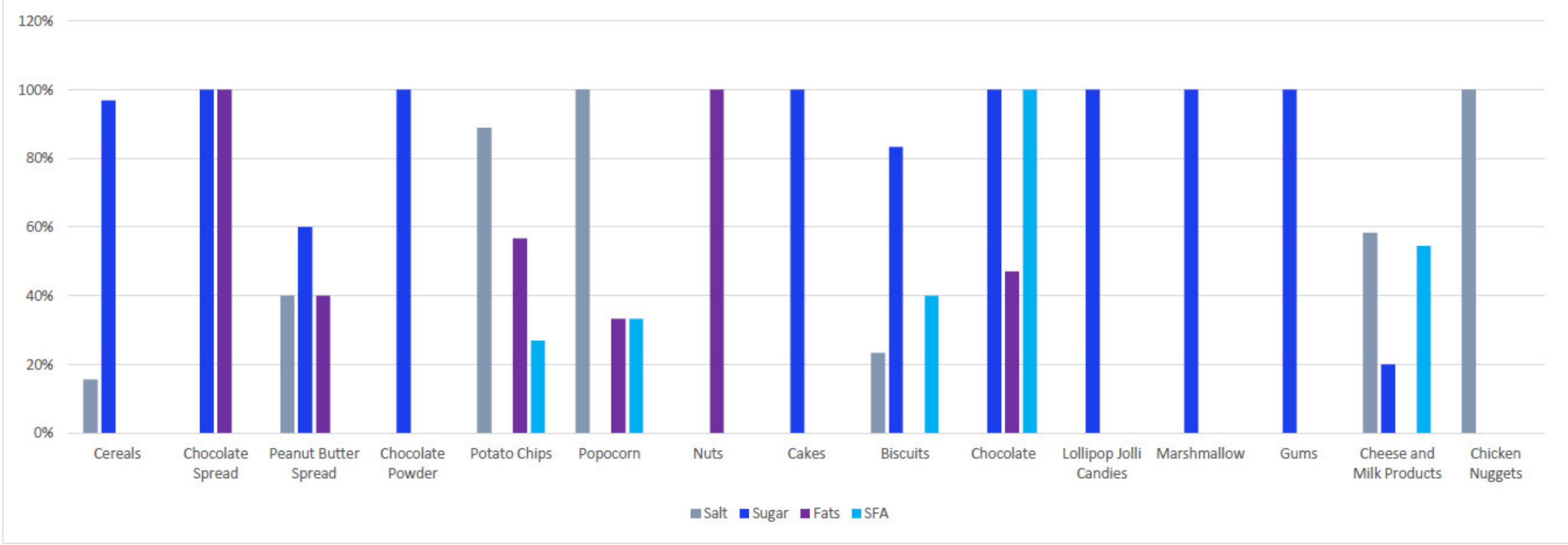

Figure 2. Percentage of children's food products with salt, sugar, total fat and saturated fatty acid composition exceeding WHO limits. SFA: saturated fatty acids. 


\section{Discussion}

The HFS is a comprehensive strategy aiming at reducing SSF and TFA composition in food items and empowering consumers to make healthy choices while shopping and eating out and in. This manuscript provided an overview of the HFS' nutrition policies and recommendations implemented in the KSA and offered insight on the level of compliance with these reforms and on the challenges faced by stakeholders.

Despite the successful launch and implementation of the HFS, compliance with the regulations can be considered moderate a few years afterwards. While some regulations had an elevated compliance rate (e.g., TFA regulation, sodium limit in breads, display of food allergens), others did not (e.g., preparation and display of nutrition labels on juices, compliance of children's food items with the SSF limits, adoption of FoPNL). Only 2\% of assessed food manufacturers adopted the FoPNL, the majority of which had a moderate content of salt, saturated fat and total fat. The rest of the policies had a fluctuation in compliance rate depending on the evaluated categories (e.g., reform on the sodium content of processed products).

To assess the effect of the HFS on product composition, comparisons were made between assessments that preceded the HFS implementation and those succeeding it (presented in our study). A cross-sectional study assessing the presence of TFA-containing products in the Saudi market, conducted in 2014-2016, revealed that $31 \%$ of the evaluated products contained TFA, and only 20\% listed TFA in the nutrient label [49]. Our study, based on SFDA surveillance conducted in 2020, showed marked improvement in TFA labeling, with $80 \%$ of the assessed products displaying TFA information as recommended by the reforms. Moreover, a cross-sectional study evaluating food products' nutrient labels and compliance with the SSF SFDA recommendations in 2016-2017 revealed that more than $20 \%$ of evaluated products did not comply with the sodium, sugar and total-fat limits [50]. Our analysis yielded similar findings. Among pediatric products, all sweet and cereal products exceeded the sugar limit, and all products in the chicken nugget, potato chip and popcorn groups exceeded the sodium limits. The products targeting all age categories showed fluctuating compliance with the sodium regulation across food categories. All in all, there was a marked improvement in TFA labeling. Yet, no significant improvements in SSF composition have been observed so far, and manufacturers seemed to be reluctant to display FoPNL for products that exceed the SSF limits. These findings highlight the need to support food manufacturers in reformulating their products and in designing FoPNL, as a gap still exists between the HFS recommendation and actual practice.

The need to design interventions to enhance the knowledge and behavior of the general population and to support restaurant owners with nutrition and food-science skills to improve the composition of their meals was also identified. A recent cross-sectional study assessed the knowledge, attitude and behavior of restaurant owners and consumers towards the energy labeling policy in food establishments. Participants' knowledge of daily caloric requirements for inactive adults was low. Even though the consumption of low and high calorie meals respectively increased and decreased by $44 \%$ and $39 \%$, $51 \%$ of subjects were less likely to eat at restaurants displaying energy content. Among restaurant owners, half of them did not know the reason behind the enforcement of this policy, and most were resistant to modifying their recipes to reduce SSF content [51]. At the consumer end, several cross-sectional studies conducted between 2019 and 2020 among adults and university students assessed their knowledge, attitude and behavior towards several dietary components, including SSF. The results revealed that participants had poor knowledge and an elevated consumption of salt, good knowledge of added sugar health risks, yet an elevated intake of sweets and fast foods and a low consumption of F\&V [52-54]. An assessment among Saudi adults prior to the HFS implementation related poor fiber intake to the expensive prices of fruits and vegetables, limited availability and dislike of their taste [55]. Through educational campaigns, the SFDA intended to address the availability of F\&V in the workplace. Yet, in view of a lack of analysis of the uptake 
and compliance with these campaigns, we are unable to assess the success rate of this component of the HFS.

At the regional level, KSA was the first country to have a "best practice TFA policy" and to implement a flat tax on carbonated beverages and energy drinks [6,56]. It was among the first to implement a HFS and encourage the use of FoPNL, along with Iran and the United Arab Emirates (UAE), and to enforce limits for sodium content in breads, along with the occupied territories of Palestine, Oman and the UAE [56,57]. Despite the early adoption of the FoPNL pledge in KSA, a minimal number of products have used it, compared to Iran, who was the first to mandate it in the region ( $2 \%$ vs. $80 \%$, respectively) [58]. Yet, the accuracy of the FoPNL labels was found to be much lower in Iran for sweets compared to our study findings in KSA [59]. This latter finding justified the lack of trust of consumers in labels and having only 15\% of the population rely on FoPNL in Iran to make shopping decisions [60].

This study has many strengths and limitations. Starting with the latter, the SFDA relied on extracting data from nutrition labels to monitor the compliance of food products, and laboratory analysis was not performed in all assessments due to the heavy financial cost incurred in such large surveillance studies. Moreover, the surveillance conducted had slight differences in methodology depending on the baseline data and assessed outcomes, with some applied on a national scale and others restricted to the city of Riyadh. Lastly, the SFDA did not collect data to analyze the interest, adoption and efficiency of the implemented educational campaigns. This study has many strengths, as it provides a comprehensive overview of policy changes in KSA using reliable data from the SFDA and presents findings of large surveillance surveys conducted shortly after the implementation of the HFS reforms.

\section{Conclusions}

This review provides a valuable resource to policymakers and stakeholders on the nutrition reforms in KSA. The HFS was introduced at a key time to alleviate the burden of NCDs on the residents' quality of life, morbidity, mortality and occurrence of heavy healthcare costs. The HFS successfully addressed important components, such as food and beverage composition and nutrient labeling for manufactured products and those available in food establishments. The HFS's positive influence was observed in the reduced TFA and sodium content of some products and the increased sales of low-calorie meals in food establishments. Yet, the HFS was neither able to improve the SSF content of many products nor able to encourage food manufacturers and restaurant owners to reformulate their products nor able to markedly influence consumers' dietary patterns. SFDA is currently working on regulations and standards to encourage national and international food producers to innovate healthy food choices. Additional measures that would be instrumental include an assessment of the response to educational campaigns and of the changes in consumers' and stakeholders' knowledge, attitude and behavior towards the SSF components of the HFS.

Supplementary Materials: The following are available online at https:/ /www.mdpi.com/article /10.3390/nu13072130/s1, Table S1: Food category of products n (\%) classified by type of FoPNL, Table S2: Nutrients based on MTL codes' criteria.

Author Contributions: Conceptualization: A.A.-J., F.F.B.S., J.J.; Data curation: L.A.A., R.A.A., A.S.A., A.A.-J., M.W.A., T.M.A., A.F.D., F.F.B.S., F.N.B.; Methodology: A.A.-J., F.F.B.S., J.J.; Resources: L.A.A., R.A.A., A.S.A., A.A.-J., M.W.A., T.A.A., A.F.D., F.F.B.S., F.N.B.; Visualization: J.J.; Writing, Original Draft: J.J.; Writing, review and editing: A.A.-J., R.A.A., F.F.B.S., J.J. Triple or quadruple initials were used for authors who had the same two letters initials. All authors have read and agreed to the published version of the manuscript.

Funding: This research received no external funding.

Institutional Review Board Statement: The study was conducted according to the guidelines of the Declaration of Helsinki, and approval was not needed since data was not collected on human subjects. 
Informed Consent Statement: Not applicable as the study did not involve humans' subjects.

Data Availability Statement: 3rd Party Data Restrictions apply to the availability of these data. Data was obtained from the Saudi Food and Drug Authority and are available from the author Faisal Fahad Bin Sunaid with the permission of Saudi Food and Drug Authority.

Conflicts of Interest: The authors declare no conflict of interest.

Disclaimer: The authors alone are responsible for the views expressed in this article and they do not necessarily represent the views, decisions or policies of WHO or the other institutions with which the authors are affiliated.

\section{References}

1. Mozaffarian, D.; Angell, S.Y.; Lang, T.; Rivera, J.A. Role of government policy in nutrition-Barriers to and opportunities for healthier eating. BMJ 2018, 361. [CrossRef] [PubMed]

2. World Health Organization. Tackling NCDs: 'Best Buys' and Other Recommended Interventions for the Prevention and Control of Noncommunicable Diseases; World Health Organization: Geneva, Switzerland, 2017.

3. Wilczek, M.M.; Olszewski, R.; Krupienicz, A. Trans-fatty acids and cardiovascular disease: Urgent need for legislation. Cardiology 2017, 138, 254-258. [CrossRef]

4. Michels, N.; Van der Meulen, K.; Huybrechts, I. Dietary Trans Fatty Acid Intake in Relation to Cancer Risk: A Systematic Review; American Society of Clinical Oncology: Alexandria, VA, USA, 2018.

5. WHO. Healthy Diet; World Health Organization: Cairo, Egypt, 2019.

6. WHO. Countdown to 2023: WHO Report on Global Trans-Fat Elimination 2020; World Health Organization: Geneva, Switzerland, 2020.

7. He, F.J.; Brinsden, H.C.; MacGregor, G.A. Salt reduction in the United Kingdom: A successful experiment in public health. J. Hum. Hypertens. 2014, 28, 345-352. [CrossRef]

8. Althumiri, N.A.; Basyouni, M.H.; AlMousa, N.; AlJuwaysim, M.F.; Almubark, R.A.; BinDhim, N.F.; Alkhamaali, Z.; Alqahtani, S.A. Obesity in Saudi Arabia in 2020: Prevalence, Distribution, and Its Current Association with Various Health Conditions. Healthcare 2021, 9, 311. [CrossRef]

9. Althumiri, N.A.; Basyouni, M.H.; AlMousa, N.; AlJuwaysim, M.F.; BinDhim, N.F.; Alqahtani, S.A. Prevalence of Self-Reported Food Allergies and Their Association with Other Health Conditions among Adults in Saudi Arabia. Int. J. Environ. Res. Public Health 2021, 18, 347. [CrossRef] [PubMed]

10. Gelhorn, H.L.; Boye, K.S.; Shalhoub, H.; Matza, L.S.; Jordan, J.B.; Alhammad, A.; Anand, S.B.; Ekhzaimy, A.A.; Strizek, A. Patient-Reported Outcomes and Impact of Type 2 Diabetes: A Cross-Sectional Study in the Kingdom of Saudi Arabia. Patient Prefer. Adherence 2020, 14, 2231-2242. [CrossRef]

11. Moradi-Lakeh, M.; El Bcheraoui, C.; Afshin, A.; Daoud, F.; AlMazroa, M.A.; Al Saeedi, M.; Basulaiman, M.; Memish, Z.A.; Al Rabeeah, A.A.; Mokdad, A.H. Diet in Saudi Arabia: Findings from a nationally representative survey. Public Health Nutr. 2017, 20, 1075-1081. [CrossRef]

12. Tyrovolas, S.; El Bcheraoui, C.; Alghnam, S.A.; Alhabib, K.F.; Almadi, M.A.H.; Al-Raddadi, R.M.; Bedi, N.; El Tantawi, M.; Krish, V.S.; Memish, Z.A. The burden of disease in Saudi Arabia 1990-2017: Results from the Global Burden of Disease Study 2017. Lancet Planet. Health 2020, 4, e195-e208. [CrossRef]

13. WHO. Saudi Arabia: Country Profile; World Health Organization: Geneva, Switzerland, 2018.

14. Al-Raddadi, R.; Bahijri, S.M.; Jambi, H.A.; Ferns, G.; Tuomilehto, J. The prevalence of obesity and overweight, associated demographic and lifestyle factors, and health status in the adult population of Jeddah, Saudi Arabia. Ther. Adv. Chronic Dis. 2019, 10. [CrossRef] [PubMed]

15. Wang, Y.-J.; Yeh, T.-L.; Shih, M.-C.; Tu, Y.-K.; Chien, K.-L. Dietary sodium intake and risk of cardiovascular disease: A systematic review and dose-response meta-analysis. Nutrients 2020, 12, 2934. [CrossRef] [PubMed]

16. Malik, V.S.; Li, Y.; Pan, A.; De Koning, L.; Schernhammer, E.; Willett, W.C.; Hu, F.B. Long-term consumption of sugar-sweetened and artificially sweetened beverages and risk of mortality in US adults. Circulation 2019, 139, 2113-2125. [CrossRef] [PubMed]

17. Ministry of Health (Ed.) World Health Survey Saudia Arabia; Ministry of Health: Riyadh, Saudi Arabia, 2021.

18. Ataey, A.; Jafarvand, E.; Adham, D.; Moradi-Asl, E. The Relationship between Obesity, Overweight, and the Human Development Index in World Health Organization Eastern Mediterranean Region Countries. J. Prev. Med. Public Health 2020, 53, 98-105. [CrossRef]

19. World Health Organization Regional Office for the Eastern Mediterranean; Alwan, A.; McColl, K.; Al-Jawaldeh, A. Proposed Policy Priorities for Preventing Obesity and Diabetes in the Eastern Mediterranean Region; World Health Organization, Regional Office for the Eastern Mediterranean: Cairo, Egypt, 2017.

20. El Mouzan, M.I.; Foster, P.J.; Al Herbish, A.S.; Al Salloum, A.A.; Al Omer, A.A.; Qurachi, M.M.; Kecojevic, T. Prevalence of overweight and obesity in Saudi children and adolescents. Ann. Saudi Med. 2010, 30, 203-208. [CrossRef] [PubMed]

21. Al-Hussaini, A.; Bashir, M.S.; Khormi, M.; AlTuraiki, M.; Alkhamis, W.; Alrajhi, M.; Halal, T. Overweight and obesity among Saudi children and adolescents: Where do we stand today? Saudi J. Gastroenterol. Off. J. Saudi Gastroenterol. Assoc. 2019, 25, 229-235. [CrossRef] 
22. Aljaadi, A.; Alharbi, M. Overweight and Obesity Among Saudi Children: Prevalence, Lifestyle Factors, and Health Impacts; Springer: Cham, Switzerland, 2020. [CrossRef]

23. Al-Qahtani, A.M. Prevalence and Predictors of Obesity and Overweight among Adults Visiting Primary Care Settings in the Southwestern Region, Saudi Arabia. Biomed. Res. Int. 2019, 2019, 8073057. [CrossRef]

24. World Health Organization; United Nations Development Programme. The Investment Case for Noncommunicable Disease Prevention and Control in Mongolia: Return on Investment Analysis and Institutional Context Analysis; World Health Organization: Geneva, Switzerland, 2017.

25. Saudi Food and Drug Authority. SFDA Launches Healthy Food Regulation Strategy Tomorrow. Available online: https: //old.sfda.gov.sa/en/food/news/Pages/f11-9-2018a1.aspx\#: \{\}:text=SFDA\%20will\%20sign \%20agreements $\% 20 f o r$, and $\% 20 f a t \% 2$ 0in\%20their\%20products (accessed on 3 March 2021).

26. Nutrition, General Directorate of Nutrition. Dietary Guidelines for Saudis: The Healthy Food Palm; Ministry of Health, Ed.; Ministry of Health: Riyadh, Saudi Arabia, 2012; pp. 1-32.

27. GSO. About GSO. Available online: https:/ / www.gso.org.sa/en/about-gso/ (accessed on 28 March 2021).

28. Moussa, H. Food and Agricultural Import Regulations and Standards Country Report, 1st ed.; Network, United States Department of Agriculture Foreign Agriculture Service and Global Agriculture Information Network; USDA: Washington, DC, USA, 2020.

29. SFDA. Trans Fatty Acids; SFDA.FD 2483; Saudi Food and Drug Authority: Riyadh, Saudi Arabia, 2018.

30. Popkin, B.M.; Hawkes, C. Sweetening of the global diet, particularly beverages: Patterns, trends, and policy responses. Lancet Diabetes Endocrinol. 2016, 4, 174-186. [CrossRef]

31. Alsukait, R.; Bleich, S.; Wilde, P.; Singh, G.; Folta, S. Sugary drink excise tax policy process and implementation: Case study from Saudi Arabia. Food Policy 2020, 90, 101789. [CrossRef]

32. Alsukait, R.; Wilde, P.; Bleich, S.N.; Singh, G.; Folta, S.C. Evaluating Saudi Arabia's 50\% carbonated drink excise tax: Changes in prices and volume sales. Econ. Hum. Biol. 2020, 38, 100868. [CrossRef]

33. Megally, R.; Al-Jawaldeh, A. Impact of sin taxes on consumption volumes of sweetened beverages and soft drinks in Saudi Arabia [version 2; peer review: 2 approved]. F1000Research 2021, 9. [CrossRef]

34. SFDA. Putting Calories on Food Establishments Menu's Selling Away-From-Home Foods; SFDA FD 20; Saudi Food and Drug Authority: Riyadh, Saudi Arabia, 2019.

35. SFDA. Sourat. Available online: https:// calories.sfda.gov.sa/ (accessed on 10 May 2021).

36. SFDA. Declaration of Allergens on Food Establishments Menus; SFDA.FD 56; Saudi Food and Drug Authority: Riyadh, Saudi Arabia, 2018.

37. SFDA. Fresh Juices, Mixes and Beverages, Sold at Juice Stores, Restaurants and Cafes; SFDA FD 5001; Saudi Food and Drug Authority: Riyadh, Saudi Arabia, 2019.

38. Malam, S.; Clegg, S.; Kirwan, S.; McGinigal, S.; Raats, M.; Shepherd, R.; Barnett, J.; Senior, V.; Hodgkins, C.; Dean, M. Comprehension and Use of UK Nutrition Signpost Labelling Schemes; Food Standards Agency: London, UK, 2009.

39. Al-Jawaldeh, A.; Rayner, M.; Julia, C.; Elmadfa, I.; Hammerich, A.; McColl, K. Improving Nutrition Information in the Eastern Mediterranean Region: Implementation of Front-of-Pack Nutrition Labelling. Nutrients 2020, 12, 330. [CrossRef]

40. SFDA. Traffic Light Labeling; SFDA.FD 42; Saudi Food and Drug Authority: Riyadh, Saudi Arabia, 2018.

41. Scarborough, P.; Matthews, A.; Eyles, H.; Kaur, A.; Hodgkins, C.; Raats, M.M.; Rayner, M. Reds are more important than greens: How UK supermarket shoppers use the different information on a traffic light nutrition label in a choice experiment. Int. J. Behav. Nutr. Phys. Act. 2015, 12, 1-9. [CrossRef] [PubMed]

42. SFDA. Requirements of Nutritional Labeling; SFDA.FD 2233; Saudi Food and Drug Authority: Riyadh, Saudi Arabia, 2018.

43. SFDA. Technical Requirements of Bread Production; SFDA.FD 2362; Saudi Food and Drug Authority: Riyadh, Saudi Arabia, 2018.

44. SFDA. SFDA.FD 57: Laban, Flavoured Laban, and Laban Drink; Saudi Food and Drug Authority: Riyadh, Saudi Arabia, 2018.

45. Public Health England. Salt Reduction Targets for 2017; Crown: London, UK, 2017.

46. SFDA. Salt Limits in Food Products; SFDA.FD 59; Saudi Food and Drug Authority: Riyadh, Saudi Arabia, 2018.

47. Tax, General Authority of Zakat and Tax. Sin Taxation 2019; General Authority of Zakat and Tax: Riyadh, Saudi Arabia, 2019.

48. United Nations. International Year of Fruits and Vegetables; Food and Agriculture Organization of the United Nations, Ed.; UN General Assembly: New York, NY, USA, 2021.

49. Kamel, S.; Hala Al, O. Trans-Fats Declaration, Awareness and Consumption in Saudi Arabia. Curr. Res. Nutr. Food Sci. 2018, 6, 748-756. [CrossRef]

50. Jradi, H.; AlMughthem, A.; Bawazir, A.A. Does the current Scope of nutrition labelling provided in the Saudi markets cope with the increasing trend of chronic disease? Res. Sq. 2020. [CrossRef]

51. Alkhaldy, A.A.; Taha, D.S.; Alsahafi, S.E.; Naaman, R.K.; Alkhalaf, M.M. Response of the public and restaurant owners to the mandatory menu energy-labelling implementation in restaurants in Saudi Arabia. Public Health Nutr. 2020, 23, 3435-3447. [CrossRef] [PubMed]

52. Hanbazaza, M.A.; Mumena, W.A. Knowledge and Practices Related to Salt Intake among Saudi Adults. Int. J. Environ. Res. Public Health 2020, 17, 5749. [CrossRef]

53. Knowledge, attitudes, and practices toward added sugar consumption among female undergraduate students in Madinah, Saudi Arabia: A cross-sectional study. Nutrition 2020, 79-80. [CrossRef]

54. Sami, R.; Bushnaq, T.; Benajiba, N.; Helal, M. Food consumption and lifestyle habits among university students in Saudi Arabia. Afr. J. Food Agric. Nutr. Dev. 2021, 21, 17711-17726. [CrossRef] 
55. Alfawaz, H.; Khan, N.; Alhuthayli, H.; Wani, K.; Aljumah, M.A.; Khattak, M.N.K.; Alghanim, S.A.; Al-Daghri, N.M. Awareness and Knowledge Regarding the Consumption of Dietary Fiber and Its Relation to Self-Reported Health Status in an Adult Arab Population: A Cross-Sectional Study. Int. J. Environ. Res. Public Health 2020, 17, 4226. [CrossRef]

56. Al-Jawaldeh, A.; Hammerich, A.; Doggui, R.; Engesveen, K.; Lang, K.; McColl, K. Implementation of WHO Recommended Policies and Interventions on Healthy Diet in the Countries of the Eastern Mediterranean Region: From Policy to Action. Nutrients 2020, 12, 3700. [CrossRef]

57. Al Jawaldeh, A.; Al-Khamaiseh, M. Assessment of salt concentration in bread commonly consumed in the Eastern Mediterranean Region. East. Mediterr. Health J. 2018, 24, 18-24. [CrossRef]

58. MG, M.A. Traffic Light' Labels to Guide Iranians toward Healthier Food. Tehran Times 7 May 2017. 2017. Available online: https:/ / www.tehrantimes.com/news/413178/Traffic-light-labels-to-guide-Iranians-toward-healthier-food (accessed on 15 May 2021).

59. Ghazavi, N.; Rahimi, E.; Esfandiari, Z.; Shakerian, A. Accuracy of the amount of trans-fatty acids in traffic light labelling of traditional sweets distributed in Isfahan, Iran. Arya Atheroscler. 2020, 16, 79-84. [CrossRef] [PubMed]

60. Esfandiari, Z.; Marasi, M.R.; Estaki, F.; Sanati, V.; Panahi, E.; Akbari, N.; Madani, R.A.; Mosberian Tanha, J. Influence of education on knowledge, attitude and practices of students of Isfahan University of Medical Sciences to traffic light inserted on food labeling. Tehran Univ. Med. J. Tums Publ. 2019, 77, 54-62. 